\title{
MICRO STICK-SLIP VIBRATION IN HYDRAULIC SERVO SYSTEMS
}

\author{
Toshiyuki HAYASE*, Satoru HAYASHI* and Kazunori KOJIMA* \\ *Institute of Fluid Science, Tohoku University \\ 2-1-1 Katahira, Sendai 980-77, Japan
}

\begin{abstract}
This paper treats stick-slip vibrations occurring in a typical computer controlled hydraulic servo system. The relevant system consists of hydraulic cylinder, servo-valve and personal computer. First, experiment was performed to reveal three different types of vibrations occurring in a conventional feedback control system. Detailed numerical analysis has been then performed to identify the main factors for occurrence of these self-excited vibrations. It is shown that the control signal generated through the D/A converter causes stick-slip vibration of small amplitude over the wide range of the control feedback gain. Increasing the feedback gain results in the other type of stick-slip vibration of larger amplitude due to the locally increased flow gain within the underlap of the servo-valve.
\end{abstract}

\section{KEY WORDS}

Stick-Slip, Hydraulic Servo System, Self-Excited Vibration, Underlap, D/A Converter

\section{INTRODUCTION}

Occurrence of a special stick-slip vibration of small amplitude ("micro stick-slip") in hydraulic control system was first pointed out by Hayashi et at [1]. They predicted this micro stick-slip vibration through their numerical analysis of the direct type hydraulic servo system and confirmed it by experiment. Unlike ordinary stick-slip vibrations, this micro stick-slip vibration can occur even if there is no difference between the static and dynamic frictions. This micro stick-slip is expected to occur generally in the dynamical system which is unstable at the neutral operating point but is stabilized by the effect of friction. However, there are few reports on the micro stick-slip so far, probably because of very small amplitude.

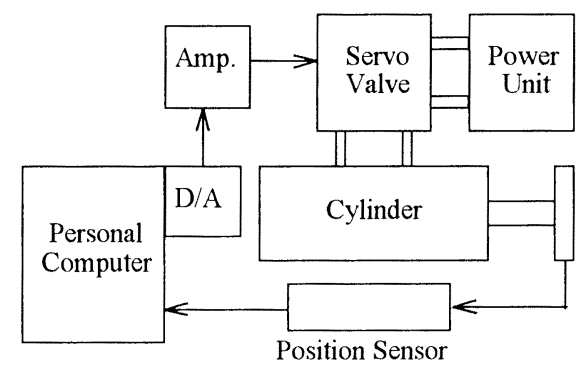

Figure 1 Experimental apparatus. 


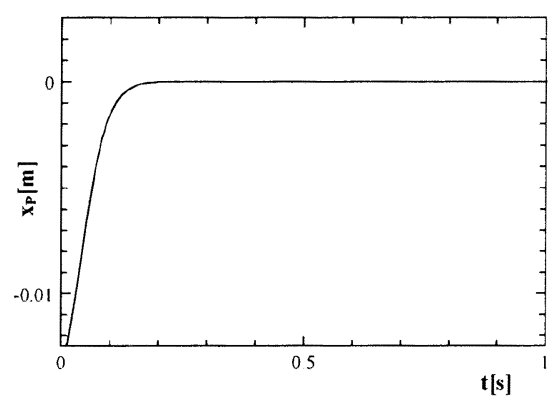

(a) Step response of piston position

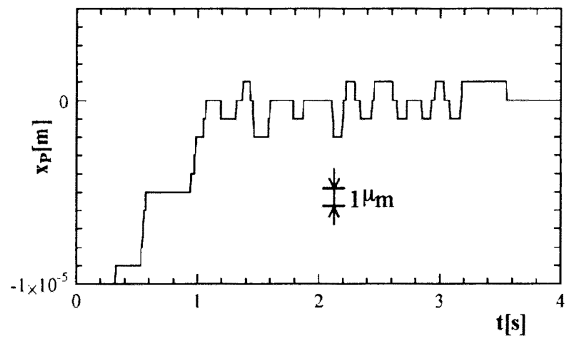

(b) Magnification of (a)

Figure 2 Experimental result $\left(\mathrm{K}_{\mathrm{p}}=1000[\mathrm{~V} / \mathrm{m}]\right)$.

This paper deals with the possibility of occurrence of the micro stick-slip in a typical hydraulic control system which consists of hydraulic cylinder, servo-valve and personal computer. First, experiment is performed for the simple proportional feedback control system in a wide range of feedback gain to characterize several types of self-excited vibrations including micro stick-slip. Detailed numerical analysis is then performed to identify the main factors for occurrence of these selfexcited vibrations.

\section{SELF-EXCITED VIBRATION IN HYDRAULIC SERVO SYSTEM}

Schematic view of the hydraulic servo system treated here is shown in Figure 1. Experimental apparatus consists of a servo valve (MOOG J661-323), hydraulic cylinder (YUKEN CJT140), hydraulic unit (YUKEN U40090), digital position sensor (SONY DG205P) and personal computer (EPSON PC286VF) with 12 bit D/A converter (ADTECH SYSTEM SCIENCE AB98-05A).

As to the control strategy, this paper deals with the fundamental proportional feedback control.

Figure 2 shows an example of the response of the piston position to the step change of reference signal. Appropriate choice of the feedback gain $\left(K_{\mathrm{p}}=\right.$ $1000[\mathrm{~V} / \mathrm{m}])$ results in a preferable overall transient response as shown in Figure 2 (a). However, the magnification of the figure by a factor of 1000 , Figure 2(b), apparently shows the occurrence of a steady stickslip vibration of double amplitude about $2 \mu \mathrm{m}$.

Double amplitude and frequency of the steady self-

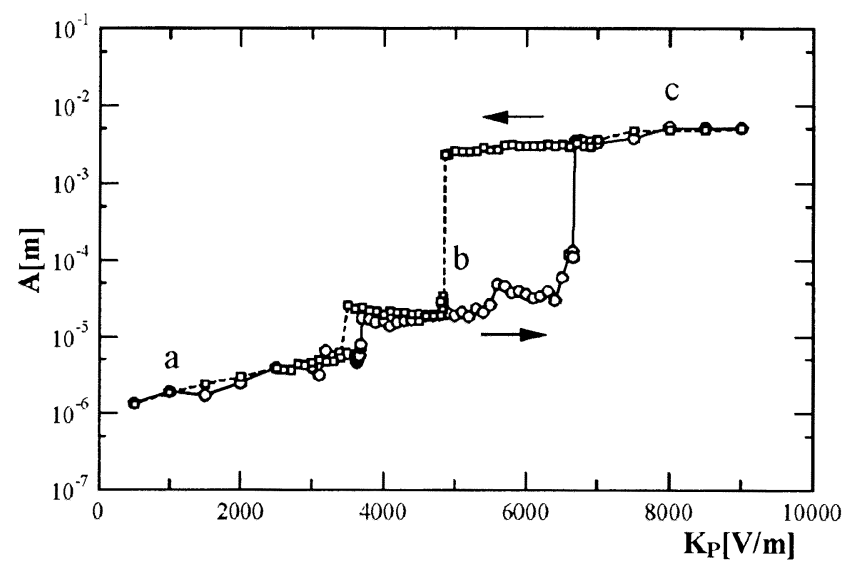

(a) Double amplitude

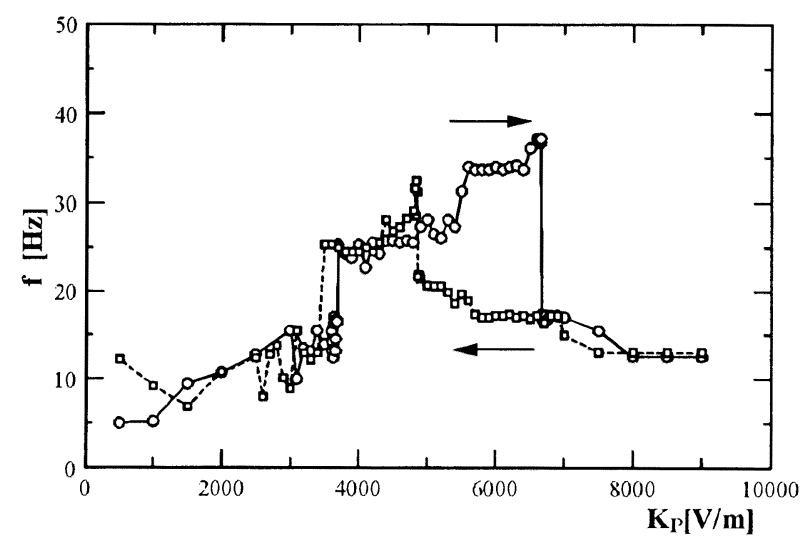

(b) Frequency

Figure 3 Characteristics of vibration with gain (Experiment).

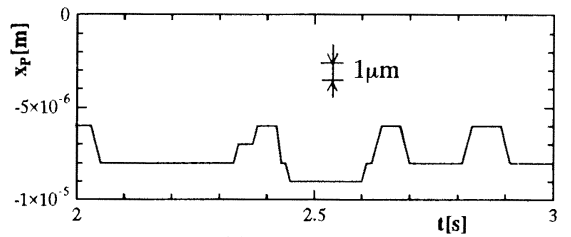

(a) $\mathrm{K}_{\mathrm{P}}=1000[\mathrm{~V} / \mathrm{m}]$

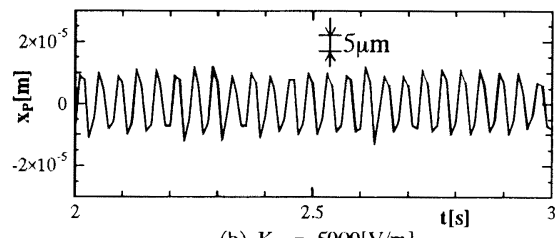

(b) $K_{p}=5000[\mathrm{~V} / \mathrm{m}]$

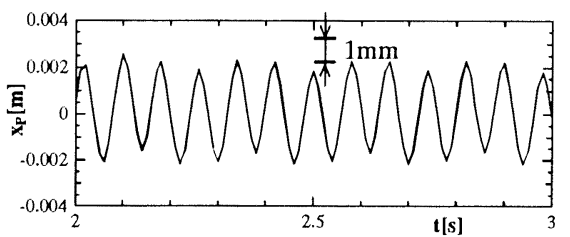

(c) $\mathrm{K}_{\mathrm{P}}=8000[\mathrm{~V} / \mathrm{m}]$

Figure 4 Wave form of vibration (experiment). 
excited vibration are plotted in Figure 3 as a function of the proportional gain, and typical wave forms of the vibration are plotted in Figure 4 for the conditions shown by $a, b$ and $c$ in Figure 3 (a). The result plotted by the solid line in Figure 3 is obtained by sequentially increasing the proportional gain of a small amount after the time interval to settle the vibration to the steady state In Figure 3, a stick-slip vibration of small amplitude occurs in a region of small feedback gain $(\mathrm{Kp}<3700[\mathrm{~V} / \mathrm{m}]$, see Figure 4 (a)). As the gain increases over the critical value of $3700[\mathrm{~V} / \mathrm{m}]$, the characteristic of the vibration changes. The amplitude and frequency of the vibration is almost doubled, while the wave form remains in stick-slip type (Figure 4 (b)). Further increment of the gain changes the vibration to the sinusoidal one of the larger amplitude (Figure 4 (c)). After increasing the gain up to $9000[\mathrm{~V} / \mathrm{m}]$, the gain is then sequentially decreased to observe the vibration. The result is plotted in Figure 3(a) with the broken line. Three types of the vibration are again observed as in the former experiment of increasing gain. However, the critical value of the amplitude where the type of the vibration changes is different from the former experiment. This hysteresis has been pointed out by Hayashi et al [1] as the multiple structure of the selfexcited vibration in the dynamical system with friction. In general, linear stability analysis of the hydraulic servo system focuses on the above mentioned large amplitude sinusoidal vibration. The present experiment revealed the existence of two different stick-slip type vibrations occurring in the region of smaller feedback gain where the system is usually considered to be stable.

In the following sections, numerical simulation is performed to investigate the main factors responsible to these stick-slip vibrations.

\section{MATHEMATICAL MODEL}

Referring to Figure 5 and Table 1, governing equations for the hydraulic servo system are presented here.

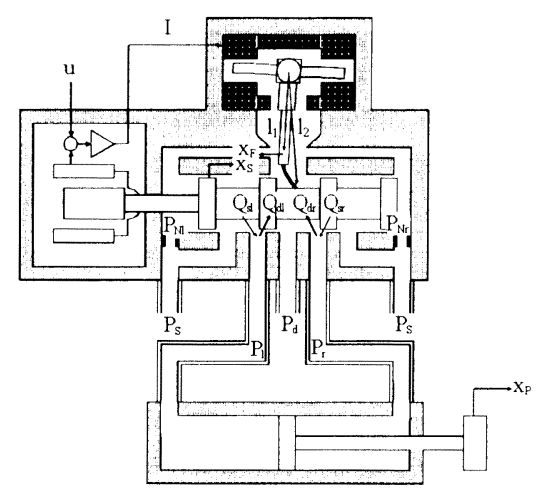

Figure 5 Hydraulic servo system.

\section{Proportional controller}

$$
u=K_{P}\left(x_{P 0}-x_{P}\right),
$$

where $u$ denotes input voltage to the servo valve, $x_{p}$ and $x_{p 0}$ denote the piston position and its reference value, respectively.

\section{Torque motor dynamics}

$$
L \dot{I}+R I=G_{a} u .
$$

\section{Nozzle flapper dynamics}

$$
\frac{J_{F}}{l_{1}} \ddot{x}_{F}=\alpha I+F_{N} l_{1}-k_{f} l_{2}\left(\frac{l_{2}}{l_{1}} x_{F}+x_{S}\right)-\frac{B_{F} l_{2}}{2} \dot{x}_{F},
$$

where $x_{F}$ denotes the flapper displacement. Flow force acting on the flapper $F_{N}$ [2] and the drag coefficient of the cylinder $B_{F}[3]$ are given as:

$$
\begin{aligned}
& F_{N}=\left(P_{N r}-P_{N}\right) A_{N}+4 \pi C_{N}^{2}\left[\left(x_{F 0}+x_{F}\right)^{2} P_{N r}-\left(x_{F 0}-x_{F}\right)^{2} P_{N l}\right], \\
& B_{F}=\frac{4 \pi \mu l_{2}}{2.002-D_{F} \dot{x}_{F} / v}
\end{aligned}
$$

\begin{tabular}{|c|c|c|}
\hline$A_{N}$ & Nozzle area $\left(\mathrm{m}^{2}\right)$ & $4.418 \times 10^{-7}$ \\
\hline$A_{p l}$ & Left side piston area $\left(\mathrm{m}^{2}\right)$ & $1.96 \times 10^{-3}$ \\
\hline$A_{P r}$ & Right side piston area $\left(\mathrm{m}^{2}\right)$ & $1.583 \times 10^{-3}$ \\
\hline$A_{S}$ & Spool area $\left(\mathrm{m}^{2}\right)$ & $8.659 \times 10^{-5}$ \\
\hline$C_{N}$ & $\begin{array}{l}\text { Discharge coefficient between nozzle and } \\
\text { flapper }\end{array}$ & 0.56 \\
\hline$C_{O}$ & Discharge coefficient of upper orifice & 0.70 \\
\hline$C_{S}$ & Discharge coefficient of metering orifice & 0.61 \\
\hline$C_{V}$ & Contraction coefficient of metering orifice & 0.98 \\
\hline$D_{F}$ & Flapper diameter $(\mathrm{m})$ & $1.6 \times 10^{-3}$ \\
\hline$D_{N}$ & Nozzle diameter $(\mathrm{m})$ & $7.5 \times 10^{-4}$ \\
\hline$F_{C}$ & Coulomb friction $(\mathrm{N})$ & 500 \\
\hline$G_{a}$ & Gain of servo amplifier & 10 \\
\hline$J_{F}$ & Inertia moment of flapper $\left(\mathrm{kgm}^{2}\right)$ & $1.0 \times 10^{-6}$ \\
\hline$k_{f}$ & feedback spring ratio $(\mathrm{N} / \mathrm{m})$ & $2.0 \times 10^{3}$ \\
\hline$L$ & Inductance of torque motor $(\mathrm{H})$ & 1.25 \\
\hline$l_{1}$ & Length of flapper (m) & $1.6 \times 10^{-2}$ \\
\hline$l_{2}$ & Length of feedback spring (m) & $4.8 \times 10^{-2}$ \\
\hline$M_{P}$ & Piston mass (kg) & 6.2 \\
\hline$M_{S}$ & Spool mass (kg) & $2.826 \times 10^{-2}$ \\
\hline$n$ & Resolution of D/A converter (bit) & 12 \\
\hline$P_{s}$ & Supply pressure (MPa) & 13.72 \\
\hline$P_{d}$ & Drain Pressure (MPa) & 0 \\
\hline$R$ & Resistance $(\Omega)$ & 500 \\
\hline$T$ & Sampling time $(\mathrm{s})$ & $3.0 \times 10^{-3}$ \\
\hline$u_{\max }$ & Max voltage of D/A converter (V) & 10 \\
\hline$w$ & Port width $(\mathrm{m})$ & $3.93 \times 10^{-3}$ \\
\hline$x_{\text {Smax }}$ & Full stroke of spool (m) & $2.0 \times 10^{-3}$ \\
\hline$\alpha$ & Gain of torque motor $(\mathrm{Nm} / \mathrm{A})$ & $9.85 \times 10^{-1}$ \\
\hline$\varepsilon$ & Underlap of spool (m) & $1.0 \times 10^{-5}$ \\
\hline$\kappa$ & Bulk-modulus of fluid $(\mathrm{Pa})$ & $7.84 \times 10^{8}$ \\
\hline$\rho$ & Density of fluid $\left(\mathrm{kg} / \mathrm{m}^{3}\right)$ & 871.6 \\
\hline
\end{tabular}

Pressure at the both sides of the spool is given by

Table 1 Computational conditions 


$$
\begin{aligned}
P_{N l} & =\frac{\xi_{1}^{2} P_{s}+\xi_{2}^{2} P_{d}}{\xi_{1}^{2}+\xi_{2}^{2}} \\
& -\frac{\left(\xi_{1}^{2}-\xi_{2}^{2}\right) \xi_{4}^{2}+2 \xi_{1} \xi_{2} \xi_{4} \sqrt{\left(\xi_{1}^{2}+\xi_{2}^{2}\right)\left(P_{s}-P_{d}\right)-\xi_{4}^{2}}}{\left(\xi_{1}^{2}+\xi_{2}^{2}\right)^{2}} \\
P_{N r} & =\frac{\xi_{1}^{2} P_{s}+\xi_{3}^{2} P_{d}}{\xi_{1}^{2}+\xi_{3}^{2}} \\
& -\frac{\left(\xi_{1}^{2}-\xi_{3}^{2}\right) \xi_{4}^{2}-2 \xi_{1} \xi_{3} \xi_{4} \sqrt{\left(\xi_{1}^{2}+\xi_{3}^{2}\right)\left(P_{s}-P_{d}\right)-\xi_{4}^{2}}}{\left(\xi_{1}^{2}+\xi_{3}^{2}\right)^{2}}
\end{aligned}
$$

where

$$
\begin{aligned}
& \xi_{1}=C_{O} A_{O} \sqrt{2 / \rho} \\
& \xi_{2}=C_{N} \pi D_{N}\left(x_{F 0}-x_{F}\right) \sqrt{2 / \rho} \\
& \xi_{3}=C_{N} \pi D_{N}\left(x_{F 0}+x_{F}\right) \sqrt{2 / \rho} \\
& \xi_{4}=A_{S} \dot{x}_{S}
\end{aligned}
$$

\section{Spool dynamics}

$$
M_{S} \ddot{x}_{S}=-B_{S} \dot{x}_{S}-k_{f}\left(x_{S}+\frac{l_{2}}{l_{1}} x_{F}\right)+A_{S}\left(P_{N l}-P_{N r}\right)-f_{l}-f_{r}
$$

where steady flow forces $f_{l}, f_{r}$ are given as

$$
\begin{array}{r}
f_{l}=4 C_{S} C_{V} w \cos \theta\left\{\left(P_{s}-P_{l}\right) \Psi\left[\varepsilon+x_{S}\right]\right. \\
\left.-\left(P_{s}-P_{r}\right) \Psi\left[\varepsilon-x_{S}\right]\right\} \\
f_{r}=4 C_{S} C_{V} w \cos \theta\left\{\left(P_{r}-P_{d}\right) \Psi\left[\varepsilon+x_{S}\right]\right. \\
\left.-\left(P_{l}-P_{d}\right) \Psi\left[\varepsilon-x_{S}\right]\right\}
\end{array}
$$

\section{Continuity in the cylinder}

$$
\begin{aligned}
& \left(V_{C l} / \kappa\right) \dot{P}_{l}=Q_{s l}-Q_{d l}-A_{P l} \dot{x}_{P} \\
& \left(V_{C r} / \kappa\right) \dot{P}_{r}=Q_{s r}-Q_{d r}+A_{P r} \dot{x}_{P}
\end{aligned}
$$

where

$$
\begin{aligned}
& Q_{s l}=C_{S} w \Psi\left(\varepsilon+x_{S}\right) \operatorname{sgn}\left[P_{s}-P_{l}\right] \sqrt{2\left|P_{s}-P_{l}\right| / \rho} \\
& Q_{s r}=C_{S} w \Psi\left(\varepsilon-x_{S}\right) \operatorname{sgn}\left[P_{s}-P_{r}\right] \sqrt{2\left|P_{s}-P_{r}\right| / \rho}, \\
& Q_{d l}=C_{S} w \Psi\left(\varepsilon-x_{S}\right) \operatorname{sgn}\left[P_{l}-P_{d}\right] \sqrt{2\left|P_{l}-P_{d}\right| / \rho} \\
& Q_{d r}=C_{S} w \Psi\left(\varepsilon+x_{S}\right) \operatorname{sgn}\left[P_{r}-P_{d}\right] \sqrt{2\left|P_{r}-P_{d}\right| / \rho}
\end{aligned}
$$

and

$$
\Psi(x)=\left\{\begin{array}{ll}
x & (x>0) \\
0 & (x \leq 0)
\end{array} .\right.
$$

\section{Piston dynamics}

$$
M_{P} \ddot{x}_{P}=A_{P l} P_{l}-A_{P r} P_{r}-\operatorname{sgn}\left[\dot{x}_{P}\right] F_{C} .
$$

The frictional force is modeled as the simple Coulomb friction in the above expression.

The output signal of the relevant servo system, the piston position $x_{p}$, is measured at each sampling period of $T$ [s]. Time delay due to processing in the controller is ignored, since the present paper deals with simple proportional control system.

Control input of the servo valve generated through the $\mathrm{n}$-bit resolution D/A converter is described as the multiple of the value of $\left(u_{\max } / 2^{\mathrm{n}-1}\right)$ in Eq. (1).

\section{NUMERICAL SIMULATION}

\section{Comparison Between Simulation and Experiment}

The governing equations for the hydraulic servo system were numerically integrated using the Runge-Kutta method of 4 th order. Time increment of $10^{-6}[\mathrm{~s}]$ is determined by test calculation. Computational conditions corresponding to the former experiment are summarized in Table 1. In computation, the effect of the Coulomb friction was treated very carefully to obtain an accurate result for stick-slip vibration of small amplitude [4].

An example of the simulation corresponding to the former experimental result (Figure 2) is shown in Figure 6. The step response of the piston position of $1.25[\mathrm{~cm}]$ is plotted for the proportional gain of $K_{P}=1000[\mathrm{~V} / \mathrm{m}]$. Overall response in Figure 6 (a) and occurrence of steady micro stick-slip in Figure 6 (b) agree well with the experimental result in Figure 2.

Next, the simulation was performed for sequentially increasing and then decreasing feedback gain corresponding to the experiment in Figures 3 and 4. The result is shown in Figures 7 and 8 . Figures 7 (a) and (b) show the double amplitude and frequency as the

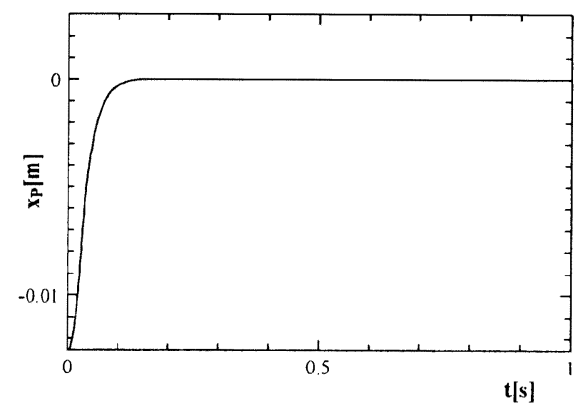

(a) Step response of piston position

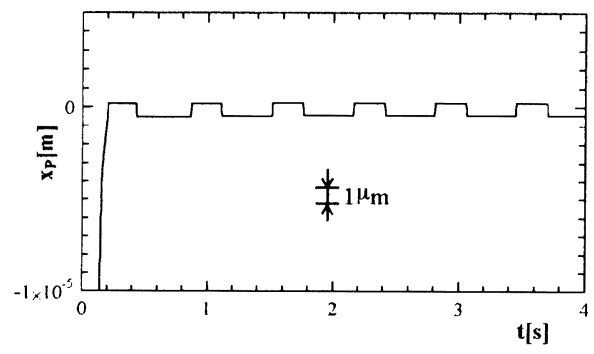

(b) Magnification of (a)

Figure 6 Numerical simulation $\left(K_{p}=1000[\mathrm{~V} / \mathrm{m}]\right)$. 
function of feedback gain, respectively. Three typical wave forms are plotted in Figure 8 for the condition $a, b$ and $c$ in Figure 7 (a). The result of the simulation shows the existence of three different types of the selfexcited vibration which agrees well with the experiment. This confirms that the present mathematical model of the system includes the main factors of the relevant selfexcited vibrations.

In the following, a numerical experiment is performed to identify the factor which is responsible to each of the three self-excited vibrations.

\section{Main Factor of Micro Stick-Slip}

Several factors are expected to relate to the occurrence of self-excited vibration: (1) discretization of the input signal due to the D/A converter, (2) nonlinear characteristic due to the underlap of the servo valve, and (3) delay due to the finite sampling time.

In order to examine the effect of these factors on each self-excited vibration, computation was performed for

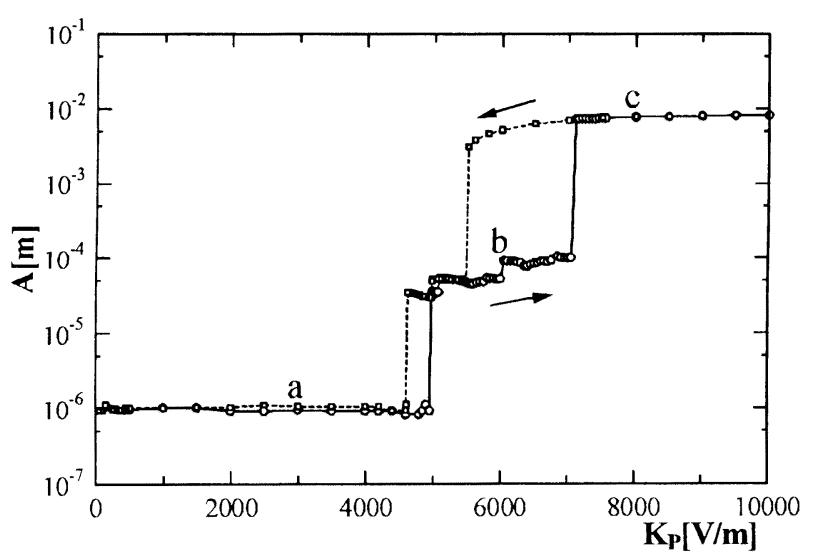

(a) Double amplitude

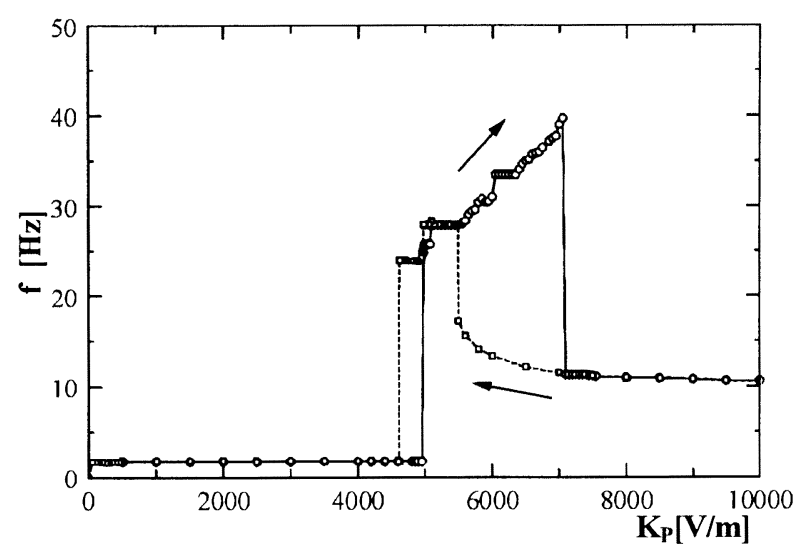

(b) Frequency

Figure 7 Characteristics of vibration with gain (simulation). the cases A, B, C and D as shown in Table 2 .

The result for the double amplitude with the feedback gain is shown in Figure 9. Case A of Figure 9 (a), the replot of Figure 7 (a), is given here as the standard result in which all the factors are considered.

First, Comparison is made between Cases A and B (Figures 9 (a) and (b)). In the result of Case B where discretization of the input signal due to the D/A converter is ignored, the small amplitude stick-slip disappeared, while the middle amplitude stick-slip and large amplitude sinusoidal vibration exist. It reveals that small amplitude stick-slip is ascribed to the discretization of the input signal. A ladder shaped input signal from the $\mathrm{D} / \mathrm{A}$ converter results in locally infinite large gain and it possibly destabilize the system. Present calculation assumes the commonly used 12 bit $\mathrm{D} / \mathrm{A}$ converter. So this small amplitude stick-slip is expected to occur widely in hydraulic servo systems. There is few reports, however, about the occurrence of this type of micro stick-slip within the authors' knowledge. This is probably due to the small amplitude and low frequency of the vibration, but the consideration of this micro stick-slip should be critical for an advanced precise positioning of the hydraulic servo system.

Next, comparison is made between the results of Cases $\mathrm{B}$ and $\mathrm{C}$. In the result of Case $\mathrm{C}$ where the effect of sampling time is further ignored from Case $B$, the critical value of the feedback gain for instability is increased and variation of the amplitude with feedback gain becomes smoother for the stick-slip of middle

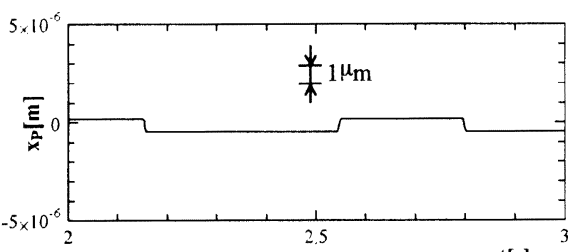

(a) $\mathrm{K}_{\mathrm{P}}=3000[\mathrm{~V} / \mathrm{m}]$

$\mathbf{t}[\mathbf{s}]$
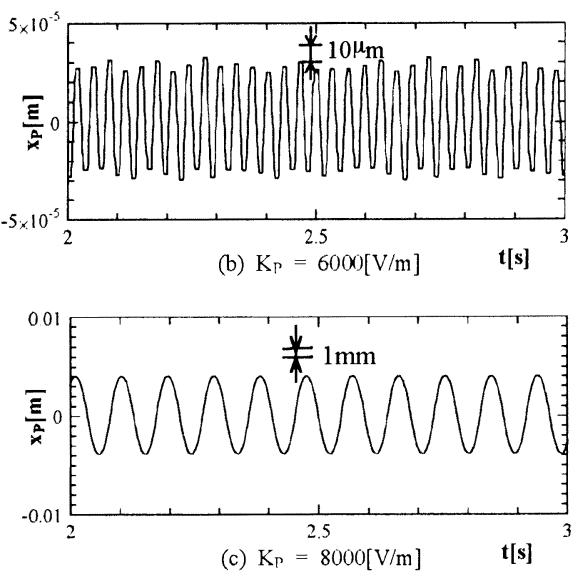

Figure 8 Wave form of vibration (simulation). 


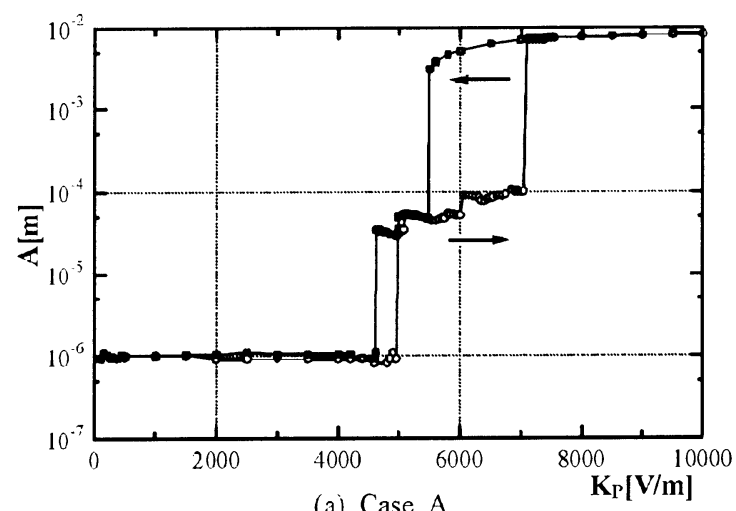

(a) Case $\mathrm{A}$

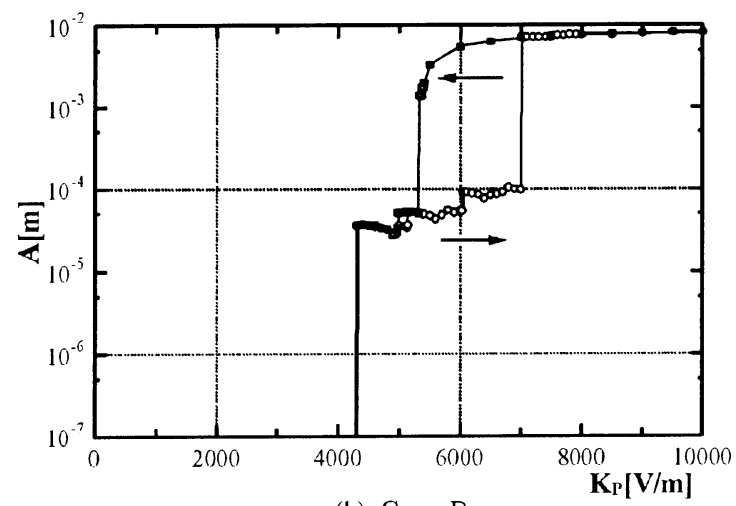

(b) Case B

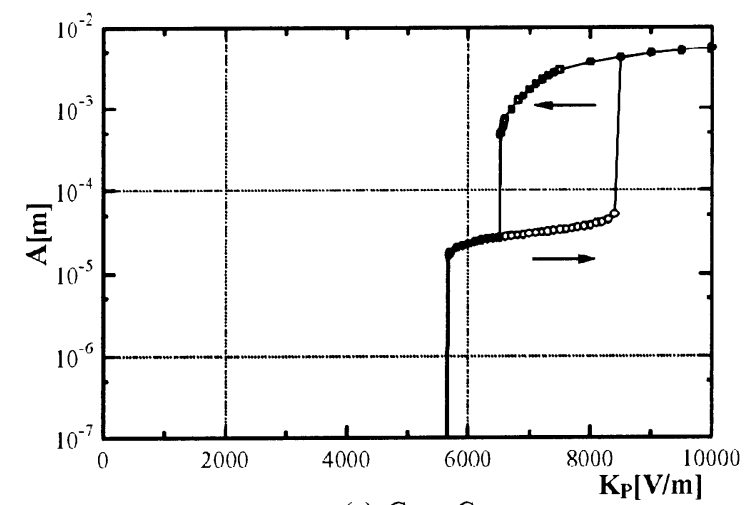

(c) Case $\mathrm{C}$

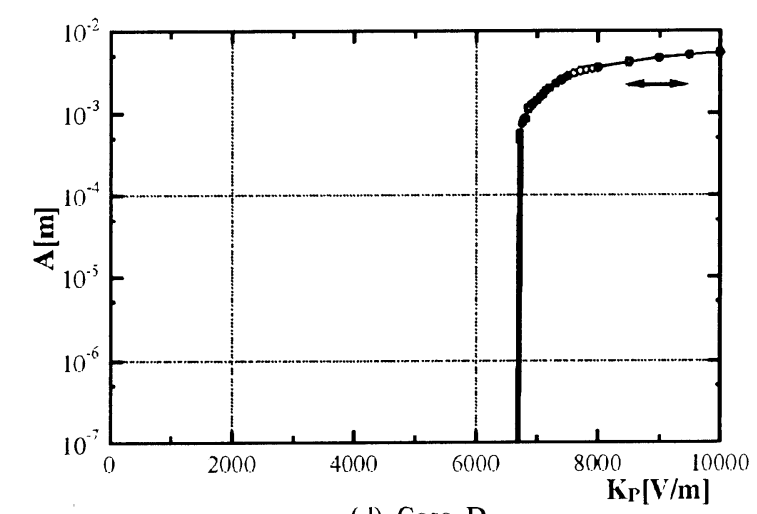

Figure 9 Self-excited vibration for cases (simulation).
Table 2 Conditions of simulation.

\begin{tabular}{|c||c|c|c||}
\hline \hline Case & D/A & Sampling & Underlap \\
\hline \hline $\mathrm{A}$ & $\mathrm{O}$ & $\bigcirc$ & $\bigcirc$ \\
\hline $\mathrm{B}$ & & $\bigcirc$ & 0 \\
\hline $\mathrm{C}$ & & & $\bigcirc$ \\
\hline $\mathrm{D}$ & $\times$ & $\times$ & $\times$ \\
\hline
\end{tabular}

amplitude, but fundamental structure of the stability characteristics is the same as the Case B.

Finally, comparison is made between the results of Cases $C$ and D. In the result of Case $D$ where the effect of the underlap of the servo valve is further ignored from Case $\mathrm{C}$, the stick-slip of middle amplitude disappears. It reveals that the middle amplitude stick-slip is ascribed to the underlap of the servo valve. Increment of the flow gain in the underlap region results in destabilization of the system. This type of the micro stick-slip was pointed out by Hayashi et al in the direct type hydraulic servo system [1].

Sinusoidal vibration of large amplitude is the result of ordinary instability due to the large feedback gain.

\section{CONCLUSIONS}

Several types of self-excited vibrations occurring in a typical computer controlled hydraulic servo system has been investigated. First, experiment was performed to reveal three different types of vibrations occurring in a fundamental proportional control system. Detailed numerical analysis has been then performed to identify the main factors of these self-excited vibrations. It is shown that the discretized control signal generated through the D/A converter causes the micro stick-slip of small amplitude over the wide range of the control feedback gain. Increasing the feedback gain results in the other type of micro stick-slip of larger amplitude due to locally increased flow gain within the underlap of servo-valve.

\section{REFERENCES}

1. Hayashi, S. et al., Effect of Coulomb Friction on Stability of Hydraulic Servomechanism, Transactions of JSME, 1993, 59-557 C, pp125-130.

2. Meritt, H. E.: Hydraulic Control Systems, (1967), John Weily \& Sons.

3. Lamb, H.: Hydrodynamics, (1932), Cambridge Univ. Press.

4. Iimura, I. and Hayashi, S., A Digital Simulation Algorithm for Hydraulic Systems subjected to Solid Friction, Proc. 4th Int. Symp. Fluid Control, Measurement and Visualization, 1994, pp391-396. 